\title{
Journal of Pediatric Neurology \&

\section{Commentary on Development of Low Postural Tone Compensatory Pattern- Predicted Dysfunction Patterns in Lower Part of the Body}

\author{
Anna Gogola*, Małgorzata Matyja and Michał Kuszewski \\ The Jerzy Kukuczka University of Physical Education, Katowice, Poland \\ *Corresponding author: Anna Gogola, Proffessor, The Jerzy Kukuczka University of Physical Education, Katowice, Poland, E-mail: aniagogola@op.pl
}

Received date: December 19, 2016; Accepted date: March 02, 2017; Published date: March 09, 2017

Copyright: (c) 2017 Gogola A, et al. This is an open-access article distributed under the terms of the Creative Commons Attribution License, which permits unrestricted use, distribution, and reproduction in any medium, provided the original author and source are credited.

\section{Introduction}

Abnormal features of development in children such as hypotony of core stability (CS) as well as hypotony and hypertony of the lower extremities muscles described by us in the previous article [1] can be considered as early symptoms of developmental coordination disorders (DCD) in the light of current knowledge. DCD is defined by the American Psychiatric Association as a marked impairment in the development of motor coordination in children. Diagnosis of DCD is made only when the impairment interferes with academic achievement or daily activities and if the coordination difficulties are not due to any known medical conditions $[2,3]$.

Literature indicates that clinical picture of children with DCD is not homogeneous-distinct differences in regard to intensity and types of motor problems [4] that in a way confirm our observations.

Many clinicians agree that there are still no clearly defined criteria of early detection of DCD features. In early infancy, proper identification of signs and symptoms is hampered by the lack of reliable tests and baseline data to the point that when motor difficulties are persistent, parents seem to be the ones who readily pick up the problems $[5,6]$.

Standardized measures of movement skills are more readily available for children of school age. Disturbances observed in the mentioned developmental periods do not appear without a reason. Motor development was initially considered as congenital feature of maturation process that was described in the neural-maturation theories. However gradually it became clear that motor development is also influenced by earlier experiences, but their impact it still an issue $[7,8]$.

Consequently, according to neural-maturation theories, abnormal motor patterns in infancy can potentially have an effect in further development not only in the form of static disturbances (body posture), but also the motor disorders (gait patterns). Wilmut et al. was analyzing gait patterns in children with DCD and have found out that there is a significant difference between gait quality in children with typical development (TD) and those with DCD [9].

The gait pattern of children with DCD was characterized by wider steps, elevated variability in the time spent in double support and stride time and greater medio-lateral velocity and acceleration compared to their peers. An elevated variability in medio-lateral acceleration was also seen in the young but not the older children with DCD. In addition, the young children showed a greater variability in velocity and acceleration in all three directions compared to the older children. The data suggest that the high incidence of trips and falls seen in children with DCD may be due to differences in the control of the center of mass (CoM).
Different variants of gait recognized as physiological occur in children without neurological dysfunctions. It seems that they might constitute the patterns of lower postural tone compensation. Some of them are related to rotational problems and some to angular problems of lower extremities, in other words, disturbances of extremities axis.

Rotational problems: in-toed gait (pigeon-toed, bandy legs), outtoeing. In-toeing is caused by one of three types of deformity: metatarsus adductus, internal tibial torsion, and increased femoral anteversion. Out-toeing is less common than in-toeing and its causes are similar but opposite to those of in-toeing. These include femoral retroversion and external tibial torsion. Angular problems include bowlegs and knock-knees [10-12]. Children should develop normal gait pattern around 6-7 years of age, but described variants of gait occur in adults sometimes.

Furthermore idiopathic toe walking [11] as a consequence of disturbed tone is mentioned. Authors also observe jumping gait that is mentioned on the Internet Websites, but there are no scientific articles about this kind of gait as a variant of normal gait. It is described only with reference to children with cerebral palsy [13]. Clumsy gait, linked to coordination disorders, is also listed [14].

In the article that commentary concerns, children with two types of compensation-spastoidal (active compensation) and athetoid (passive compensation) have been described. Clinical experience indicates that:

Active compensation can be accompanied by outtoeing gait, jumping gait and bowlegs

Passive compensation can be accompanied by gaits with internal rotation that are intoeing gait and knock-knees. It seems that also clumsy gait is mostly noted in athetoid children

Authors believe that idiopathic gait can be observed in children with both types of compensation. In spastoidal type it can be a consequence of shortening of hamstring and gastrocnemius muscles. In athetoid type it can occur as manifestation of Putti mechanism that facilitates maintaining of balance through increased anterior pelvis tilt and shift of center of gravity beyond hips, in front of knee joints and beyond ankle joints $[15,16]$.

Having an opportunity of writing commentary to our previous article we would like to refer critically to the arbitrary assumption that hypotony of transversus abdominis ( $\operatorname{TrA}$ ) constitute the reason of development of compensation patterns. We have assumed that muscles of local system in children play the same role as in adults. In adults the role of the local system is to maintain the mechanical stiffness and a neutral spine. Thus, muscle stiffness in the local system provides the primary mechanism of trunk stability [17] and stiffness induced by muscle activation increases stability [18]. We have not taken into account that development of CS region is kind of a process and 
individual muscles prepare themselves gradually to act as in adults. We doubt that $\operatorname{Tr} \mathrm{A}$ in children is as indispensable in control of this region as in adults. However, observations indicate high variability of maintenance of this muscle during postural tasks in children [19]. Further researches of core stability region development will help to determine whether hypotony of these muscles in such early development stage can be recognized as a reason of compensation patterns development. Currently the least we can say is that observed abnormal motor patterns in infancy can be symptoms of DCD development and require therapy that normalizes postural tone. According to theory of motor learning early therapy can contribute towards sustainable changes in motor control. Motor learning refers to the permanent change in an individual's motor performance brought about as a result of practice or intervention. Motor learning principles help identify how we can best manipulate the individual, the task and the environment to influence long-term neuroplastic changes to promote an individual's motor performance [20].

Another factor that might have impact on development of motor patterns and coordinative abilities are fascias. It is worth acknowledging that issue of connective tissue significance is more often investigated currently:

1. In aspect of its contribution in transmission of loads in movement system [21], and

2. In scope of secondary influence of fascia functioning disturbances on coordination and proprioception [22]. It is possible that disturbances of development of connective tissue have an impact on muscle tone layout and motor control and in the immediate future the issue will constitute substantial direction of researches [23].

\section{References}

1. Brusic V, Rudy G, Honeyman G, Hammer J, Harrison L (1998) Prediction of MHC class II-binding peptides using an evolutionary algorithm and artificial neural network. Bioinformatics 14: 121-130.

2. Gogola A, Saulicz E, Kuszewski M, Matyja M, Mysliwiec A (2014) Development of low postural tone compensatory patterns in childrentheoretical basis. Dev Period Med 13: 374-379.

3. American Psychiatric Association (1994) Diagnostic and statistical manual of mental disorders DSMIV-TR. 4th ed. Washington, DC, USA: APA.

4. Watkinson EJ, Causgrove DJ, Cavaliere N, Calzonetti K, Wilhelm L (2001) Engagement in playground activities as a criterion for diagnosing developmental coordination disorder. Adapt Phys Act Q 18: 18-34.

5. Visser J (2003) Developmental coordination disorder: A review of research on subtypes and comorbidities. Hum Mov Sci 22: 479-493.

6. Wilson PH, McKenzie BE (1998) Information processing deficits associated with developmental coordination disorder: A meta-analysis of research findings. J Child Psychol Psyc 39: 829-840.
7. Jongmans MJ (2005) Early identification of children with developmental coordination disorder. In children with developmental coordination disorder (Eds, Sugden, DA and Chambers ME), London: Whurr publishers, pp: 155-167.

8. Hadders-Algra M (2008) Development of postural control. In: Carlberg EB, Hadders-Algra $M$, editors. Postural control: A key issue in developmental disorders. 1 ed. London: Mach keith press.

9. Campbell SK, Linden DWV, Palisano RJ (2007) Physical therapy for children. 3 ed. St. Louis Missouri: Saunders Elsevier.

10. Wilmut K, Du W, Barnett AL (2016) Gait patterns in children with developmental coordination disorder. Exp Brain Res 234: 1747-1755.

11. Sass P, Hassan G (2004) Lower extremity abnormalities in children. Am Fam Physician 69: 1049 .

12. Sutherland D, Olshen R, Biden E, Wyatt M (1988) The development of mature walking. Clinics in Devel Med 104/105, Mackeith Press: Oxford Blackwell Scientific Pubs. Ltd, Philadelphia

13. Lincoln TL, Suen PW (2003) Common rotational variations in children. J Am Acad Orthop Surg 11: 312-320.

14. Rodda J, Graham HK (2001) Classification of gait patterns in spastic hemiplegia and spastic diplegia: A basis for a management algorithm. Eur J Neurol 5: 98-108.

15. Sigmundsson H (2005) Disorders of motor development (clumsy child syndrome). J Neural Transm Suppl, pp: 51-68.

16. Putti V (1922) Raporti statici fra piede e ginocchio nell' arto paraliitico. Chir. Org Movim 6: 125-138.

17. Fasco M, Hernigon P, Tigani D (2015) Challenges in total knee arthroplasty (TKA) 69-93 In: Surgical techniques in total knee arthroplasty and alternative procedures Affatato S.[red] Elsevier, Cambridge.

18. Gardner-Morse MG, Stokes IA (1998) The effects of abdominal muscle co-activation on lumbar spine stability. Spine (Phila Pa 1976) 23: 86-91.

19. Kim Y, Shim JK, Son J, Pyeon HY, Yoon B (2013) A neuromuscular strategy to prevent spinal torsion: Backward perturbation alters asymmetry of transversus abdominis muscle thickness into symmetry. Gait Posture 38: 231-235.

20. Gogola A, Gnat R, Dziub D, Gwózdz M, Zaborowska M (2016) The impact of the neurodevelopmental traction technique on activation of lateral abdominal muscles in children aged 11-13 years. NeuroRehabilitation 39: 183-190.

21. Ezekiel HJ, Lehto NK, Marley TL, Wishart LR, Lee TD (2001) Application of motor learning principles: The physiotherapy client as a problemsolver. III: Augmented feedback. Physiother Can 53: 33-39.

22. Turrina A, Martinez-Gonzalez MA, Stecco C (2013) The muscular force transmission system: Role of the intramuscular connective tissue. J Bodyw Mov Ther 17: 95-102.

23. Stecco A, Stern R, Fantoni I, De Caro R, Stecco C (2016) Fascial disorders: Implications for treatment. PM R 8: 161-168. 